\title{
Building and Sustaining Community in an Online EdD Program
}

\author{
Ray R. Buss \\ Arizona State University \\ ray.buss@asu.edu \\ Leigh Graves Wolf \\ Arizona State University \\ leigh.wolf@asu.edu
}

\begin{abstract}
In this essay, we have described how we build and sustain community in our online EdD program. Initially, we discussed our understanding of community and its influence on our efforts. Then, we discussed three important theoretical frameworks - Wenger's Community of Practice, Garrison et al.'s Community of Inquiry, and Morris and Stommel's Critical Digital Pedagogy —and how those frameworks helped to shape our efforts in building and sustaining an online community. Next, we discussed strategies/processes that we have successfully used to build and sustain community in our online program. These strategies were grouped around three kinds of relationships that have been central to community formation, interaction, and continuation-student-to-student, student-to-faculty, and student-to-broader-community. We discussed specific strategies such as the Leadership Challenge, Doctoral Research Conference, an online program "Hub," comprehensive and immediate feedback, mentoring, and Leader Scholar Communities, that we have found to be particularly useful in building and sustaining an online community.
\end{abstract}

KEYWORDS

building online community, online community, EdD program, sense of community, connectedness

Three theoretical perspectives have guided and continue to influence our efforts in building community in our online program. Wenger's (1998; Wenger et al., 2002) communities of practice (CoP) framework has served as one of the theoretical perspectives guiding our online efforts for building and sustaining community. Garrison et al.'s (2000) community of inquiry (Col) has provided the second theoretical framework that has directed our efforts with respect to developing and maintaining community in our online program. Additionally, Morris and Stommel's (2018) work on critical digital pedagogy has influenced our efforts in developing community. Before examining the theoretical perspectives more closely, we have offered a brief discussion about community.

\section{COMMUNITY}

To begin, our own notions of community have been influenced by the work of McMillan and Chavis (1986) and Rovai (2002a, b, c). McMillan and Chavis maintained that there were four elements of community including (a) membership, feelings of belonging and relationship to others; (b) influence, making a difference in the group and the group mattering to the individual; (c) integration of members; and (d) emotional connections based on shared thoughts, feelings, and experiences. Their model has encouraged us to consider a range of factors that have been essential to the establishment and maintenance of community.

New articles in this journal are licensed under a Creative Commons Attribution 4.0 United States License.
Rovai $(2002 a, c)$ extended these important components of community, which were developed outside of the context of online learning, to the online learning environment. In his important work, Rovai (2002c) added the concepts of (a) connectedness and (b) learning in online settings. Rovai's (2002c) definition of connectedness was quite broad and incorporated concepts like a feeling of belonging and acceptance, cohesion, and bonding that resulted in trust, which fostered group member interaction and support within the group. By comparison, Rovai (2002c) suggested learning was "the feeling that knowledge and meaning are actively constructed within the community, that the community enhances the acquisition of knowledge and understanding, and that the learning needs of its members are being satisfied" (p. 322). Thus, for Rovai, learning was something students in an online class did together. In our own efforts, we have extended Rovai's concepts about connectedness and learning to the whole online program.

The importance of community to students engaged in doctoral study has been recognized by others writing about doctoral students' program experiences, as well. Lovitts (2001) recognized the importance of community in student retention and program completion. Consistent with this overall notion, Ali and Kohun (2006, 2007) found that students who were more strongly integrated into graduate programs with peers and faculty members were more likely to be retained and complete the program. the Education Doctorate: A Knowledge Forum on the EdD (CPED) cpedinitiative.org 


\section{Communities of Practice}

In their writing on communities of practice (CoP), Wenger et al. (2002) suggested CoP were characterized by three elements: "a domain of knowledge, which defines a set of issues; a community of people who care about this domain; and the shared practice that they are developing to be effective in the domain" (p. 27, italics in original). In the next sections, we have discussed these aspects more fully.

Wenger et al. (2002) maintained that the domain helped to establish a common ground that encouraged "members to contribute and participate, guide[d] their learning, and [gave] meaning to their actions" (p. 27-28). In the current context, the domain consisted of various matters associated with students' efforts in an online EdD program. For example, the domain included a broad range of issues such as course content, course activities to learn the content, logistical aspects of working online, connecting with peers in an online setting, and many other features associated with the program or working in the online environment.

With respect to community, Wenger et al. (2002) claimed, "The community creates the social fabric of learning. A strong community fosters interactions and relationships based on mutual respect and trust" (p. 28). Thus, the community afforded members opportunities to interact with one another and develop relationships that facilitated and supported their actions in the program. For example, community members including students and faculty members shared information and ideas about courses, coursework requirements, and research efforts, which provided students with academic support. Further, student-to-student and faculty-to-student relationships afforded opportunities in which community members provided emotional support.

By comparison, "The practice is a set of frameworks, ideas, tools, information, styles, language, stories, and documents that community members share. ... the domain denotes the topic... [whereas] the practice is the specific knowledge the community develops, shares, and maintains" (Wenger et al., 2002, p. 29, italics in original). Thus, the practice component of the CoP consisted of the various ideas, tools, information, processes, and so on relevant to completing coursework, engaging with students and faculty members, carrying out research efforts, and completing other aspects of the program as they connected with one another in the online setting. More specifically, practice included knowledge about how to respond to class discussions, how to extend research efforts across the program, how to structure sections of the dissertation in practice, and so on.

\section{Community of Inquiry (Col)}

Garrison et al.'s (2000) Col has focused on three components of online learning - teaching presence, social presence, and cognitive presence. Anderson et al. (2001) defined teaching presence as "the design, facilitation, and direction of cognitive and social processes for the purpose of realizing personally meaningful and educationally worthwhile learning outcomes" (p. 5). Accordingly, Anderson et al.'s discussion of teaching presence was focused on instructional design, developing understanding, and instruction in the subject matter. Although such a definition was appropriate for individual courses, it had limited utility when programs were being considered. More recently, Kumar and Dawson (2018) suggested, "teaching presence in an online professional doctorate can be more accurately termed faculty presence, [because] ... multiple faculty members not only teach, support, and mentor online doctoral students ... but also administer the program" (p. 54). Notably, Kumar and Dawson claimed faculty presence was essential to ensure effective instruction and mentoring, comprehensive curriculum design, and sound program leadership, which were necessary components related to the design and implementation of a successful online professional, doctoral program. Thus, Kumar and Dawson's notion of faculty presence extended teaching presence in a more comprehensive fashion to all facets of programs, not just program design and instruction.

Consistent with these ideas, faculty members in the $\mathrm{EdD}$ in the Mary Lou Fulton Teachers College at Arizona State University carefully designed and implemented a program featuring strong instruction and highly supportive mentoring. Moreover, consistent with the concept of strong instruction, they developed and implemented a well-articulated, sequenced curriculum that facilitated students' development as scholarly and influential practitioners. In doing so, they fostered and supported a strong online community by using various class- and research-related components such as thorough feedback on assignments, on-going communications, an EdD Program Hub, virtual group and individual mentoring in Leader Scholar Communities, and so on, which are described more fully in later sections of the article.

Garrison (2009) maintained social presence was, "the ability of participants to identify with the community (e.g., course of study), communicate purposefully in a trusting environment, and develop interpersonal relationships by way of projecting their individual personalities" (p. 352). At its core, Garrison noted social presence entailed several critical elements including open, effective communication and group cohesion. Notably, group cohesion involved building social relationships, which have influenced students' interaction and persistence in doctoral programs (Kumar \& Dawson, 2018). Further, Kumar and Dawson claimed communication and trust were critical in establishing a sense of community, which was essential to providing an environment characterized by collaboration and mutual support. Relationships in the program have been developed by implementing a strong cohort model using CoP as a foundation, fostering engagement with one another through class and program requirements such as the Leadership Challenge Fishbowl and Doctoral Research Conference, which exemplify several program features.

In their definition of cognitive presence, Garrison and his colleagues (2000) claimed cognitive presence was "the extent to which participants ... are able to construct meaning through sustained communication [discourse]" (p. 89). Thus, the focus of cognitive presence has been on students' engagement with course content. Sustained discourse has been a key component of our EdD program. In our program, two types of sustained discourse have been fostered including student-to-student discourse and student-tofaculty discourse. Both types have been essential to student engagement with the material. Notably, the sustained discourse and reflective aspects of cognitive presence exhibited by students in our program have been fostered, supported, and sustained by faculty and social presence.

\section{Critical Digital Pedagogy}

In their recent work on critical digital pedagogy (CDP), which built upon the work of hooks (1995), Inman Berens (2015), and 
Weinberger (2002), Morris and Stommel (2018) claimed a crucial aspect of CDP was focusing "its practice on community and collaboration." In particular, Morris and Stommel maintained CDP encouraged new perspectives about how teachers and students were connected socially, politically, and emotionally in an online learning environment. Further, they suggested that high levels of engagement and interaction would be foundational to effective outcomes in online and hybrid settings. Taken together, these assertions were consistent with our thinking and program efforts about how to build and sustain community in the online setting.

Notably, Morris and Stommel (2018) asserted that those using technology for learning have been overly focused on efficiency and effectiveness, a tool-based orientation for using technology. Instead, they suggested putting the learner first by reconsidering the human and interactive aspects of learning as students and faculty members learned alongside one another. This perspective was captured powerfully when the authors advocated that CDP provided open educational milieus in which the focus was on dialogue between students and faculty members. In our own efforts, we have focused on providing opportunities for students and faculty members to engage in consequential dialogue throughout the program as evidenced in the next sections of this essay.

\section{STUDENT-TO-STUDENT CONNECTIONS FOSTERING COMMUNITY}

In this section, we offer examples of program components that are designed to foster and sustain community in our program. The first, the Leadership Challenge Fishbowl occurs fairly early in the program, during the second term, and affords students opportunities to make connections, build relationships, and engage in consequential dialogue with their peers. The second, Knowledge Building Google Site also transpires during the second term and gives students an opportunity to collectively construct a resource for theories relevant to problems of practice. The third, the Doctoral Research Conference (DRC), is experienced by students throughout the program and affords opportunities to make connections with those at various stages in the program and with those who are working on similar problems of practice. Finally, we briefly discuss the use of social media to support connections among students in our EdD program.

\section{Leadership Challenge Fishbowl}

The purpose of the Leadership Challenge is to foster development of collaboration and leadership skills and to build community. The work of the leadership challenge is deeply rooted in the ideas of Wenger's CoP (Wenger, 1998; Wenger et al., 2002). The leadership challenges help students realize that their action research will not be done in isolation. We want to scaffold the collaboration and leadership skills through the activity that will be necessary for the students as they conduct on-going course and research work.

To complete the assignments students are divided into small groups of five (cohorts are typically comprised of approximately 20 students) and two of the four groups are asked to record a 15-minute discussion based upon a provocative question (e.g., "How can I positively influence my CoP through participation in a 'broader configuration' of networks?"). Students prepare for the discussion by gathering quotes from Wenger's (1998) text and course readings and then meet to record a video using Zoom. The video is then shared with the other groups who were not tasked with recording so they can view "the fishbowl." After participating in (or viewing) the recordings, all students are asked to identify a leadership behavior with which they want to experiment over the next week or two in their workplace and to enact that change. For example, students may develop a community of learners in their workplace, collaborate with school colleagues in their work setting, or lead implementing improvements at work. Then, as the culminating task, students are asked to write about how their change in behavior affected others in their CoP to briefly tell the story of what happened and then reflect on their efforts.

Students report enjoying the Leadership Challenge Fishbowl activity for several reasons. First, they appreciate the meaningful peer interaction when preparing for and recording the video. Although the video is only 15 minutes long, the students meet for a while before recording it to discuss their approach, giving online students the rare opportunity for casual interactions. Further, students report being surprised at the results of incremental and intentional changes in behaviors, setting them up for success in their future cycles of action research. Finally, as online instructors, it serves as a unique opportunity to engage with students in an asynchronous-synchronous way, giving us an opportunity to glimpse into their learning and their work with one another.

\section{Knowledge Building Google Site}

The purpose of the Knowledge Building Google Site assignment is to collectively construct knowledge to expand personal perspectives and build a repository that can help generate change in the existing conditions of students' practice contexts. The site can serve as a starting point for frameworks relevant to teaching, learning, leadership, and innovation. It is impossible to cover all theories and this activity gives students an opportunity to focus on concepts relevant to them, in a shared and open space. Over the course of a semester, students contribute several pages to a shared Google Site which lists several learning, leadership, and innovation theories, frameworks, and models. Students generate and co-edit entries, allowing them a scholarly and collegial opportunity to collaborate and make connections around similar theoretical interests.

\section{Doctoral Research Conference}

The Doctoral Research Conference (DRC) https://drc.asu.edu is an online forum for students in the EdD Program in the Mary Lou Fulton Teachers College to share and receive feedback on their ongoing doctoral research with members of their respective cohorts, as well as members of other cohorts and Teachers College faculty members. The DRC represents an academic forum for doctoral students to disseminate their ongoing research. The conference has been held online since the spring of 2017 and serves as an opportunity for the face-to-face and online cohorts to interact to build community as one cohesive community. Keynote speakers for the DRC have included CPED officials, ASU administrators, and EdD alumni.

The day of the conference, students present for 10 minutes about the progress of their research. Students are grouped based on similarity of the problem of practice and each presentation "room" of four to five students has a range of experience (some recently began the program, some are preparing to defend their dissertations, and 
so on). A faculty moderator is assigned to each room, allowing the students to connect with the wider Mary Lou Fulton Teachers College academic community. The conference takes place at the end of each spring semester and is a celebratory experience for all involved. Generally, students have reacted positively to the DRC as evidenced in the following students' comments:

- "It was great to see students who were at the end of their EdD program and their presentations. It was helpful to see where we're headed."

- "I liked the camaraderie that was ... present in each room I went to. Such a supportive environment. I liked seeing the process and the presentations of cohorts ahead of me and receiving advice from more experienced students."

- "The diversity of research and problems of practice was amazing. I also liked hearing people at different [levels] of their research - those who had just defended versus those who were in their first cycle of research. As a first semester starter, I have a long way to go!"

- "I enjoyed being mixed with people I did not know and were in different parts of the program."

- "Students and moderators are all very kind and supportive. This reflects the culture of the EdD program. Please continue the unwavering support and further develop the student-centeredness of the program."

\section{Social Media: \#ASUEdD and Facebook Groups}

Social media fills a gap for informal connections between students in online graduate programs (Greenhalgh et al., 2016). There is an "official" Facebook group for the program, however, many cohorts create closed Facebook groups which they report using frequently to support each other throughout the program. There has been light (yet increasing) use of the \#ASUEdD hashtag on Twitter. We have been tracking the use of the hashtag over the past two years and use tends to swell during the Doctoral Research Conference-and then a small group of students across cohorts (and some faculty) use the hashtag to connect and tag each other in communications.

\section{STUDENT-TO-FACULTY MEMBER (AND PROGRAM) COMMUNITY CONNECTIONS}

In addition to fostering student-to-student connections through various approaches, students in the EdD program are afforded many opportunities to connect with faculty members and support staff members. These opportunities include a Hub, podcasts, Slack collaboration application, feedback, and Leader Scholar Communities, which are discussed in this section of this article.

\section{EdD in Leadership \& Innovation Information Canvas Hub}

The Hub is intended to be a "one stop shop" for the EdD community. It is a continually developing space curated by the EdD Program Committee, with input from the broader EdD community. The Hub is located in the university course management system, Canvas. All EdD students, faculty, and staff members are enrolled in the Hub and have access to all of the resources. The key feature of the Hub is a digital repository of every ASU Leadership and Innovation EdD dissertation. The repository uses a technology called Leganto Reading Lists that connects directly to our library and the ProQuest dissertation database. The dissertation archive is a powerful programmatic artifact and helps students see their work as a part of a larger legacy. In addition to the dissertation archive, the Hub houses advising resources and serves as a vehicle for program announcements.

\section{Podcasts}

In an effort to continue to strengthen connections in the EdD community, a podcast was piloted in the fall of 2019. Podcasting as a medium has great potential for connecting online students (Ferguson, 2010). To date, four episodes of the podcast have been produced, and one of the episodes was coproduced with a student who voluntarily expressed interest in helping with the production. Additionally, the program has received emails from students suggesting topics (and also expressing interest in assisting with production). The program plans on continuing the podcasts in the spring of 2021.

\section{Slack}

Arizona State University has a university-wide installation of Slack. Slack is "a collaboration hub that enables real-time communications and connections in a searchable platform for realtime messaging, content sharing, learning, and more" (Arizona State University Technology Office, n.d.). Several EdD courses use Slack as an alternative to (or extension of) Canvas discussion forums. Through Slack, students can participate in threaded discussions, respond with emojis, and share various multimedia. Additionally, they can contact the instructor through direct messaging. Some instructors are now holding office hours via Slack. The medium provides faculty with another platform for maintaining connections with students.

\section{Feedback}

High quality interpersonal interactions with instructors are a strong indicator of student success in online programs (Jaggars \& $\mathrm{Xu}, 2016)$. Feedback is paramount to our instruction and mentoring in the online EdD program. We facilitate high quality feedback in several ways:

- Scheduled mentor check-in meetings

- Google docs including Reading Reflection Journals and Key Understandings, Muddiest Points, Burning Questions, and Connections/Applications (KMBC) Journals

- Weekly videos

\section{Mentor Check-in Meetings}

In each course, students are encouraged to contact their instructors at any time, however, we purposefully embed at least two scheduled meetings into the coursework to allow an opportunity for synchronous connections. Often, students will discuss their on-going action research efforts and receive feedback and direction from their mentor (course instructor or Leader Scholar Community faculty mentor). 


\section{Reading Reflection Journals (RRJ) and Key Understandings, Muddiest Points, Burning Questions, and Connections/Applications (KMBC) Journals and Google Docs}

The commenting feature in Google docs is an invaluable tool for creating and sustaining relationships with students and supporting them with their writing. Once students realize that faculty are deeply invested in their work (literally at a line by line basis at times in a Google Doc) then, they start to see this as a supportive and individualized space to learn. We highlight two assignments (RRJ and $\mathrm{KMBC}$ ) that take advantage of these interactive features in Google Docs.

The specific purpose of the RRJ assignment is as follows:

- To give students a baseline understanding of implicit theories of teaching, learning, and innovation

- To deepen understanding of the challenges of defining and facilitating learning

- To make connections to things already known. What we can learn from new information and new experiences depends on what we already know. Learning is enhanced when we explicitly and intentionally create links between old knowledge and new knowledge.

In a similar way, the KMBC allows the instructor to comprehend how well students have understood the material in the reading(s). In the $\mathrm{KMBC}$ assignments students are asked to:

- Identify "Key Understandings (K)" from the reading(s) using six to eight bullet points.

- Identify the "Muddiest Point (M)" for you in this week's readings (i.e., what are you having problems understanding?). Explain what you think might be your struggle with this idea. To what do you attribute this difficulty? (e.g., Is the writing unclear? Do you have inadequate background knowledge? Does it counter your previous beliefs?).

- Identify at least one "Burning Question (B)" related to the readings. What do you want to know more about or understand better? Why?

- Make at least one "Connection/Application to Scholarly Practice (C)." How do these ideas relate to your workplace, community of practice, research work, or problem of practice?

This powerful learning and reflection pattern creates opportunities for dynamic weekly dialogues between students and instructors within a Google Doc. For example, faculty members who have taught the earlier research and inquiry classes have advantageously used these dialogue opportunities to clarify and respond to students' questions related to research, research designs, and research procedures.

\section{Leader Scholar Communities--Sustaining Communities}

Although Leader Scholar Communities (LSC) are not strictly speaking a faculty-to-student connection because students also develop strong student-to-student connections during the LSC, we discuss it here as a means to sustain the community, which we have earlier developed among students. LSC are groups of five to six students and one faculty member who work together in a small CoP during the last two years of the program to ensure students make timely progress on their Dissertation in Practice (DiP) including devising a proposal, implementing the DiP by collecting and analyzing data, and writing and defending the final version of the DiP. As students undertake the dissertation, they typically feel more isolated and that they are receiving less support than when they were engaged in their coursework (Ali \& Kohun, 2006, 2007; Lovitts, 2001). Thus, LSC are implemented to provide academic, social, and emotional support to students throughout the dissertation process (Buss \& Allen, 2020). The faculty member chairs all the students' committees, facilitates their DiP work, and supports the dissertation process. Buss and Allen (2020) have written extensively about LSC. The focus of our description of LSC will be on implementation of LSC in the online setting to ensure continued connections to other students, faculty members, and the program, which were central features of dissertation support proposed by Ali and Kohun (2007).

In our online program, LSC meetings have been conducted using Zoom and structured to provide content appropriate to the DiP work. For example, substantive content related to theories, research methods, data collection and analysis, and so on continued to foster connections to faculty members and the program. Similarly, logistical matters like securing committee members, completing Graduate College paperwork, meeting timelines for writing, and so on also supported on-going connections with the program and faculty members.

Notably, LSC continue to support student-to-student connections as well, in both formal and informal ways. In a more formal way, students are encouraged to secure a student, peer/critical friend to provide feedback on their writing. Informally, some students convene before or after their scheduled online LSC meeting to begin or resume discussions of content, logistical issues, and so on from the LSC meeting (Craig Mertler, personal communication, Nov. 15, 2017). "These actions, both formal with the chair and [peers and] informal with peers, attested to the power of ... fostering a community among online LSC participants" (Buss \& Allen, 2020, p. 5).

\section{STUDENT-TO-BROADER-COMMUNITY CONNECTIONS}

We have primarily focused our efforts on fostering connections of students with faculty members and students with students as discussed, above. Nevertheless, we have also helped students to connect with other communities that are critical to their success in our EdD program. These community connections include associations with (a) the broader Arizona State University community, (b) those in their own workplace setting, and (c) individuals from the larger research community.

To assist our students in connecting to the broader Arizona State University community, we require them to reach out to a faculty member who has expertise in the area of their problem of practice. Early in the program we have students engage in an assignment where we provide a mentored opportunity and discussion to help students feel comfortable searching for and reaching out to faculty (both inside the institution and beyond). Students search through the internal faculty directory and online for researchers related to their emerging areas of expertise. They then draft (and eventually send) communications to the faculty members and researchers. For online EdD students, this is especially important since forging these connections online is one of the ways (beyond coursework and the 
Doctoral Research Conference) to meet faculty who may be able to serve on their dissertation committee.

With respect to fostering student connections to their workplace settings, we promote those efforts in the Leadership Challenges that we ask students to complete. Students' action research work and efforts on their DiP necessitate that students be engaged in collaborative efforts in their workplaces. By participating in the Leadership Challenges, students are provided with affordances for them to build and enhance their collaborative relationships with their workplace peers whether those peers are teachers, advising staff members, student workers, or whatever the roles of those who will be collaborators/participants in the projects.

We also help students to build connections with the professional community who are working on research related to the students' problems of practice. In one of the Leadership Challenges, we require students to connect with someone virtually to build their professional connections and network. Specifically, we ask them to reach out to someone to make online connections by using Linkedln, joining a blog, or sending an email to connect with a researcher who is doing work in their area of interest. This has led to some remarkable opportunities for students. First, they have had opportunities to discuss with prominent researchers, the researchers' perspectives and garner resources to inform students' efforts.

Second, in some instances, individuals have agreed to serve as one of the DiP committee members. Notably, students have benefited personally and professionally from these connections.

\section{CONCLUSION}

In this essay, we describe how we have enacted various strategies and processes to build and sustain an active learning community in an online EdD program. Our efforts at community development are guided by three theoretical frameworks including Wenger's (1998; Wenger et al., 2002) Communities of Practice, Garrison et al.'s (2000) Community of Inquiry, and Morris and Stommel's (2018) Critical Digital Pedagogy. We also describe specific strategies/processes that we have successfully used to build and sustain a community in our online program. These strategies arise from three kinds of relationships that have been central to community formation, interaction, and continuation-student-tostudent, student-to-faculty, and student-to-broader-community.

With respect to applying these community building and sustaining strategies to other programs, we offer the following questions for consideration. What strategies are you currently using in your program to foster student-to-student discourse? Which of the ones discussed here might be used to increase student connections with one another? For example, would use of less formal, but student-directed approaches using social media increase a sense of community among your online students? Additionally, would use of a small-group strategy similar to the Leadership Challenge Fishbowl or Knowledge Building Google Site activities be helpful in building community? Or would implementation of a Doctoral Research Conference aid students in being connected to one another and the program?

Moreover, what strategies are your programs using to support student-to-faculty member interaction and discourse? Would the use of a program "Hub" be beneficial in connecting your scholarly community? Similarly, would providing podcasts, offering weekly videos, conducting check-ins, or using Slack or a similar tool help to connect students in your program with faculty members? Notably, do assignments and coursework afford opportunities for faculty members to dialogue with students to facilitate learning and the community building that can occur through feedback? Specifically, would the use of carefully crafted assignments like Reading Reflection Journals (RRJ), Key Understandings, Muddiest Points, Burning Questions, and Connections/Applications (KMBC) Journals, and Google Docs aid faculty members in providing feedback to create dialogues that develop and sustain online community with students? Further, would employing Leader Scholar Communities or a similar approach aid your program to sustain community during the Dissertation in Practice phase of your program?

Finally, what strategies are you currently using to facilitate student-to-broader-community interaction and discourse? Do you ask students to connect with other faculty members at the institution? Are students required to make stronger local workplace connections as part of your program? Additionally, do you ask students to make connections to scholars in the broader research community, especially those who are working on research related to students problems of practice? Taken together, we hope you find the strategies we describe in this essay to be productive in inspiring ways to build and maintain community in your online programs as well.

\section{REFERENCES}

Ali, A., \& Kohun, F. (2006). Dealing with isolation feelings at IS doctoral programs. International Journal of Doctoral Studies, 1, 21-33. http://ijds.org/Volume1/IJDSv1p021-033Ali13.pdf

Ali, A., \& Kohun, F. (2007). Dealing with social isolation to minimize doctoral attrition-A four stage framework. International Journal of Doctoral Studies, 2, 33-49. http://www.ijds.org/Volume2/IJDSv2p033-049Ali28.pdf

Anderson, T., Rourke, L., Garrison, D. R., \& Archer, W. (2001). Assessing teaching presence in a computer conferencing context. Journal of Asynchronous Learning Networks, 5(2), 1-17.

Arizona State University Technology Office. (n. d.). https://uto.asu.edu/slack

Buss, R. R., \& Allen, J. G. (2020). Leader scholar communities: Supporting EdD students' dissertation in practice efforts. Impacting Education: Journal on Transforming Professional Practice, 5(3), 1-7. doi: 10.5195/ie.2020.98

Ferguson, L. A. (2010). The effects of podcasting on student perceptions of community within the online learning environment. (UMI Number: 3407166) [Doctoral dissertation, TUI University]. ProQuest Dissertations and Theses Global.

Garrison, D. R. (2009). Communities of inquiry in online learning: Social, teaching and cognitive presence. In C. Howard et al. (Eds.), Encyclopedia of distance and online learning (2nd ed., pp. 352-355). IGI Global.

Garrison, D. R., Anderson, T., \& Archer, W. (2000). Critical inquiry in a textbased environment: Computer conferencing in higher education model. The Internet and Higher Education, 2(2-3), 87-105.

Greenhalgh, S. P., Rosenberg, J. M., \& Wolf, L. G. (2016). For every tweet there is a purpose: Twitter within (and beyond) an online graduate program. Proceedings of Society for Information Technology \& Teacher Education International Conference 2016 (pp. 2044-2049) http://www.editlib.org/p/171972

hooks, b. (1995). Teaching to transgress: Education as the practice of freedom. Routledge.

Inman Berens, K. (2015, January 5). Want to 'save the humanities'? Pay adjuncts to learn digital tools. Disrupting the Digital Humanities. http://disruptingdh.com/want-to-save-the-humanities-pay-adjuncts-tolearn-digital-tools

Jaggars, S. S., \& Xu, D. (2016). How do online course design features influence student performance? Computers and Education, 95, 270-284 https://doi.org/10.1016/j.compedu.2016.01.014 
Kumar, S., \& Dawson, K. (2018). An online doctorate for researching professionals: Program design, implementation, and evaluation. AU Press.

Lovitts, B. E. (2001). Leaving the ivory tower: The causes and consequences of departure from doctoral study. Rowman \& Littlefield.

McMillan, D. W., \& Chavis, D. M. (1986). Sense of community: A definition and theory. Journal of Community Psychology, 14(1), 6-23.

Morris, S. M., \& Stommel, J. (2018). An urgency of teachers: The work of critical digital pedagogy. Pressbooks.

Rovai, A. P. (2002a). Building sense of community at a distance. The International Review of Research in Open and Distributed Learning, 3(1). http://www.irrodl.org/index.php/irrodl/article/view/79/152

Rovai, A. P. (2002b). Development of an instrument to measure classroom community. The Internet and Higher Education, 5(3), 197-211.

Rovai, A. P. (2002c). Sense of community, perceived cognitive learning, and persistence in asynchronous learning networks. The Internet and Higher Education, 5(4), 319-332.

Weinberger, D. (2002). Small pieces loosely joined: $A$ unified theory of the web. Perseus Pub.

Wenger, E. (1998). Communities of practice: Learning, meaning, and identity. Cambridge University Press.

Wenger, E., McDermott, R., \& Snyder, W. M. (2002). Cultivating communities of practice. Harvard Business School Press. 